\title{
Contemporary contribution of orthodontics to the public health: A brief commentary paper
}

\author{
Fabio Ciuffolo* \\ viale Matrino 124, 65013 Città Sant'Angelo (PE), Italy
}

\begin{abstract}
This brief commentary paper summarizes the impaction of malocclusion and orthodontic treatment on the quality of life, then the possible implication on the public health. This gives to orthodontics a crucial role to promote health, improving the quality of life trough proper strategies, supported by public policies in according with Word Health Organization recommendation.
\end{abstract}

\section{Background}

In recent years several authors reported the impaction of malocclusion [1] and orthodontic treatment [2] on the Oral HealthRelated Quality of Life (OHRQoL) - that is comfort when eating, sleeping and engaging in social interaction, in self-esteem and satisfaction with respect to the oral health [3].

Some of these Authors, Kragt, et al. [1] showed that patients between the age of 11 and 14 were most likely to have any impact of malocclusions on OHRQoL; the older the patients were, the more their malocclusion affected their quality of life. Indeed, the biggest impaction was seen in adolescents older than 14 years old. On the contrary, the influence of malocclusion on OHRQoL was less in younger patients.

For this reason childhood should be the best period to intercept those malocclusion affecting OHRQoL, in order to reduce the risk for experiencing discomfort in physical, social and psychological aspects of the oral health in future teenagers. These objectives would be coherent with the World Health Organization (WHO) definition of health that says: "Health is a state of complete physical, mental and social well-being and not merely the absence of disease or infirmity" [4].

It is worth of reminding that the development of the mouth plays a crucial role in the development of the face, hence it is important to promote a harmonious development of the mouth identifying the correct timing and treatment strategies of malocclusion in order to improve oral health-related quality of life, then health in children and adolescents.

In this view, a research performed by Seehra J, et al. found that orthodontic treatment might have positive effect on adolescents experiencing bullying related to their malocclusion and their OHRQoL [2]. Other Authors [5] observed that Children at high risk for sleepdisordered breathing were characterized by reduced quality of life, reduced nasopharyngeal and oropharyngeal sagittal dimensions, palatal crossbite, and narrow maxillary and mandibular arches. They also concluded that rapid maxillary expansion might aid in improving the quality of life in children with a narrow maxilla [5].

Another positive effect, observed by using the rapid maxillary expansion, on the quality of life was the reduction of nocturnal enuresis related to the nasal airway, nasal breathing, and plasma osmolality, as an indicator for antidiuretic hormone [6]. Finally, the correction of class II was also described as a procedure which improved nocturnal breathing in adolescents, by increasing the volume of the upper airways after the correction of mandibular retrognathism [7].

The above evidences showed that treatment of malocclusion might lead to an improved quality of life essentially by two mechanisms: positive effect on (1) social-emotional domain of OHRQoL [1-3] and (2) improved breathing [5-7]. Social-emotional OHQoL domain reflects the appearance of the dentition, then the possible related bullying, reduced self-esteem, and being ashamed of laughing [8-11]. Instead, rapid maxillary expansion and treatment of class II malocclusion due to retrognathic mandible might produce increasing of volume of the upper airways, then better breathing [5-7].

\section{Clinical implication}

Since malocclusions largely impact the social-emotional domain, OHRQoL is suggested to be a multidimensional concept, influenced by individual factors, not stable, but dynamic, over time. For this reason, Orthodontists needs to be aware of OHRQoL when the treatment option are suggested, because they might stabilize as well as destabilize mental and social well-being, which are necessary to be on health [4]. The social-emotional domain also indicates that lay people may perceive different outcomes compared with those usually wanted by the orthodontists, with possible conflicts if the obtained outcomes would not be the same.

Another clinical implication concerns the crucial role played by the orthodontists in identifying patients with a craniofacial morphology consistent with pediatric OSAS (retrusive chin, steep mandibular

Correspondence to: Fabio Ciuffolo, viale Matrino 124, 65013 Città Sant'Angelo (PE), Italy, Tel: +39-339-1431761, Fax: +39-(0)85-4683127, E-mail: fabio@ studiociuffoloferritto.it

Key words: orthodontics, quality of life, public health, OHRQoL

Received: November 23, 2016; Accepted: December 05, 2016; Published: December 08, 2016 
plane, vertical direction of growth and a tendency toward Class II malocclusion) [12]. In the presence of snoring, inability to breathe through the nose, significant allergies, asthma or obesity, the clinician should refer the patient to an otolaryngologist [12].

In conclusion, nowadays orthodontics may give a significant contribution to the public health by identifying and treating properly the malocclusions that impact quality of life. Hence, policies dedicated to promote prevention and treatment strategies of malocclusions and the related breathing disorders, in children as well as in adolescents, are needed in according with the recommendations of WHO [13].

\section{References}

1. Kragt L, Dhamo B, Wolvius EB, Ongkosuwito EM (2016) The impact of malocclusions on oral health-related quality of life in children-a systematic review and metaanalysis. Clin Oral Invest 20: 1881-1894.[Crossref]

2. Seehra J, Newton JT, Dibiase AT (2013) Interceptive orthodontic treatment in bullied adolescents and its impact on self-esteem and oral-health-related quality of life. Eur J Orthod 35: 615-621.[Crossref]

3. Sischo L, Broder HL (2011) Oral health-related quality of life: what, why, how, and future implications. J Dent Res 90: 1264-1270.[Crossref]

4. Preamble to the Constitution of the World Health Organization as adopted by the International Health Conference, New York, 19-22 June, 1946; signed on 22 July 1946 by the representatives of 61 States (Official Records of the World Health Organization, no. 2, p. 100) and entered into force on 7 April 1948.
5. Katyal V, Pamula Y, Daynes CN, Martin J, Dreyer CW, et al. (2013) Craniofacial and upper airway morphology in pediatric sleep-disordered breathing and changes in quality of life with rapid maxillary expansion. Am J Orthod Dentofacial Orthop 144: 860-871.[Crossref]

6. Al-Taai N, Alfatlawi F, Ransjö M, Fakhry S (2015) Effect of rapid maxillary expansion on monosymptomatic primary nocturnal enuresis. Angle Orthod 85: 102-108.[Crossref]

7. Schütz TC, Dominguez GC, Hallinan MP, Cunha TC, Tufik S (2011) Class II correction improves nocturnal breathing in adolescents. Angle Orthod 81: 222-228.[Crossref]

8. ZhangM, McGrath C, Hägg U (2006) The impact of malocclusion and its treatment on quality of life: a literature review. Int $J$ of Paediatr Dent 16: 381-387.[Crossref]

9. Seehra J, Fleming PS, Newton T, DiBiase AT (2011) Bullying in orthodontic patients and its relationship to malocclusion, selfesteem and oral health-related quality of life. $J$ Orthod 38: 247-256.[Crossref]

10. De Baets E, Lambrechts H, Lemiere J, Diya L, Willems G (2012) Impact of self-esteem on the relationship between orthodontic treatment need and oral health-related quality of life in 11- to 16-yearold children. Eur J Orthod 34: 731-737. [Crossref]

11. Shah ND, Arruda A, InglehartMR (2011) Pediatric patients' orthodontic treatment need, quality of life, and smiling patterns - an analysis of patient, parent, and provider responses. J Public Health Dent 71: 62-70.[Crossref]

12. Flores-Mir C, Korayem M, Heo G, Witmans M, Major MP, et al. (2013) Craniofacial morphological characteristics in children with obstructive sleep apnea syndrome: a systematic review and meta-analysis. J Am Dent Assoc 144: 269-277.[Crossref]

13. http://www.who.int/features/qa/health-promotion/en/ (August 2016).

Copyright: $\odot 2016$ Ciuffolo F. This is an open-access article distributed under the terms of the Creative Commons Attribution License, which permits unrestricted use, distribution, and reproduction in any medium, provided the original author and source are credited. 